\title{
Bacterial population succession and adaptation affected by insecticide application and soil spraying history
}

\author{
Hideomi Itoh ${ }^{1}$, Ronald Navarro ${ }^{2}$, Kazutaka Takeshita ${ }^{1}$, Kanako Tago $^{3}$, Masahito Hayatsu ${ }^{3}$, \\ Tomoyuki Hori ${ }^{2}$ and Yoshitomo Kikuchi ${ }^{1 *}$ \\ ${ }^{1}$ Bioproduction Research Institute, National Institute of Advanced Industrial Science and Technology (AIST), Sapporo, Japan \\ 2 Research Institute for Environmental Management Technology, National Institute of Advanced Industrial Science and Technology (AIST), Tsukuba, Japan \\ ${ }^{3}$ Environmental Biofunction Division, National Institute for Agro-Environmental Sciences, Tsukuba, Japan
}

Edited by:

Shin Haruta, Tokyo Metropolitan

University, Japan

Reviewed by:

Raffaella Balestrini, Consiglio

Nazionale delle Ricerche, Italy

Joerg Graf, University of

Connecticut, USA

Satoshi Ishii, Hokkaido University,

Japan

*Correspondence:

Yoshitomo Kikuchi, Bioproduction

Research Institute, National Institute

of Advanced Industrial Science and

Technology (AIST), 2-17-2-1,

Tsukisamu-higashi, Toyohira-ku,

Sapporo, Hokkaido 062-8517, Japan

e-mail:y-kikuchi@aist.go.jp
Although microbial communities have varying degrees of exposure to environmental stresses such as chemical pollution, little is known on how these communities respond to environmental disturbances and how past disturbance history affects these community-level responses. To comprehensively understand the effect of organophosphorus insecticide application on microbiota in soils with or without insecticide-spraying history, we investigated the microbial succession in response to the addition of fenitrothion [O,O-dimethyl O-(3-methyl-p-nitrophenyl) phosphorothioate, abbreviated as MEP] by culture-dependent experiments and deep sequencing of $16 \mathrm{~S}$ rRNA genes. Despite similar microbial composition at the initial stage, microbial response to MEP application was remarkably different between soils with and without MEP-spraying history. MEP-degrading microbes more rapidly increased in the soils with MEP-spraying history, suggesting that MEP-degrading bacteria might already exist at a certain level and could quickly respond to MEP re-treatment in the soil. Culture-dependent and -independent evaluations revealed that MEP-degrading Burkholderia bacteria are predominant in soils after MEP application, limited members of which might play a pivotal role in MEP-degradation in soils. Notably, deep sequencing also revealed that some methylotrophs dramatically increased after MEP application, strongly suggesting that these bacteria play a role in the consumption and removal of methanol, a harmful derivative from MEP-degradation, for better growth of MEP-degrading bacteria. This comprehensive study demonstrated the succession and adaptation processes of microbial communities under MEP application, which were critically affected by past experience of insecticide-spraying.

Keywords: fenitrothion, organophosphorus insecticide, soil microbes, deep sequencing, Burkholderia, methylotroph

\section{INTRODUCTION}

Biological communities are exposed to varying levels of environmental stresses or disturbances such as global warming, typhoon, drought, and bush fire (Phillips et al., 2009; O'Connell and Nyman, 2011; Peñuelas et al., 2013; Rota et al., 2014), and little is known about community succession and adaptation processes under such environmental stimuli. In addition to naturally occurring environmental disturbances, chemical insecticides have been developed and used worldwide to control agricultural, hygienic, and household pest insects. Although insecticides have revolutionized modern agriculture and sanitation in terms of pest management, abuse of usage sometimes causes serious problems including environmental pollution from its residues, health hazard, unexpected effects on non-targeted organisms, and evolution of insecticide-resistant insects (Whalon et al., 2008; Diez, 2010). Thus, insecticide-spraying is thought to be a man-made, yet strong, environmental stress on natural organisms.
Organophosphorus insecticide, a general name referring to insecticides containing a phosphoester bond, is one of the most widely used insecticides. It includes a number of commercially available chemicals such as diazinon, malathion, and dichlorvos (Singh and Walker, 2006; Singh, 2009). The chemical compounds found in organophosphorus insecticide show high mammalian toxicity as well as insecticidal activity by inhibiting acetylcholinesterase (AchE), causing overstimulation of the cholinergic synapses by the overaccumulation of acetylcholine (da Silva et al., 2013). Fenitrothion [O,O-dimethyl O-(3-methylp-nitrophenyl) phosphorothionate, abbreviated as MEP] is one of the organophosphorus compounds commonly used because of its broad-spectrum activity and less mammal toxicity. In natural fields, MEP can be degraded photochemically, but is mainly degraded by soil bacteria. Biodegradation pathways of MEP were first investigated in forest soils using $\mathrm{C}^{14}$-labeled MEP (Spillner et al., 1979) and are currently described in the International Programme on Chemical Safety IPCS (1992). In 
microorganisms, MEP is hydrolyzed to 3-methyl-4-nitrophenol and then finally decomposed to $\mathrm{CO}_{2}$ through a phenol ring cleavage pathway (IPCS, 1992). Previous culture-dependent studies reported that members of the genera Burkholderia, Pseudomonas, Cupriavidus, Corynebacterium, Arthrobacter, and Sphingomonas have been identified as MEP-degraders, some of which use the compound as a sole carbon source (Tago et al., 2006; Zhang et al., 2006; Kim et al., 2009). Considering that only a tiny fraction of environmental bacteria is culturable (Wilson and Piel, 2013), culture-independent as well as culture-dependent approaches are pivotal to comprehensively understand microbial dynamics in soils after spraying with MEP, as previously mentioned (Jacobsen and Hjelmsø, 2014).

Recent advances in sequence technologies, the so-called next generation sequencing (NGS), provide a faster and simpler alternative to previously established techniques for the comprehensive investigation of microbial community structures (Moorthie et al., 2011). Fairly recent works using NGS include the evaluation of microbial community compositions of soils polluted with organochlorine pesticides including Dichlorodiphenyltrichloroethane (DDT), hexachlorocyclohexane $(\mathrm{HCH})$, and 2-chloro-4-ethylamino-6-isopropylamino-striazine (ATZ) (Fang et al., 2014). Based on the metagenomic survey of functional genes, these studies have suggested that diverse bacterial species complement one another to degrade these organochlorides (Fang et al., 2014).

In crop fields, biodegradation of the insecticides is one of the pivotal factors affecting the recovery and sustainability of soil ecosystems. Furthermore, it has been reported that one or more previous applications of the same insecticides and/or other structurally-analogous insecticides frequently result to less persistence of the insecticide in the environment (Felsot, 1989). In soil environments where the same insecticide has been continuously sprayed, it has been hypothesized that insecticide-degrading microbes grow by assimilating the insecticide and are enriched in the soil, which cause excessively enhanced biodegradation of the sprayed insecticides (Arbeli and Fuentes, 2007). However, it remains unclear how microbial communities transit under and adapt to insecticidespraying and how the history of insecticide-spraying affects these succession and adaptation processes of soil microbial communities.

By combining the culture-independent approach using the NGS technique with culture-dependent isolation of MEP-degrading bacteria, we investigated the detailed process of microbial succession when MEP was sprayed on fieldcollected soils with or without a history of MEP-spraying prior to collection. Among the collected soils, one has been sprayed with MEP at least for 4 years and the other has never been sprayed with MEP nor with other organophosphorus compounds. The NGS analysis combined with culturedependent approach clearly demonstrates previously unseen dynamics of soil microbiota during MEP-spraying, highlighting the different responses of microbiota against the experimental MEP-spraying in the different types of soil, and identifying the key players of MEP-degradation in soil environments.

\section{MATERIALS AND METHODS SOILS}

We collected two andisol soils from agricultural fields located at the National Institute for Agro-Environmental Sciences (Tsukuba, Ibaraki, Japan; $36^{\circ} 0^{\prime} \mathrm{N}, 140^{\circ} 1^{\prime} \mathrm{E}$ ): soil S (Sprayed soil) was collected from a crop field that had been sprayed with MEP for at least 4 years $\left[\mathrm{pH}\left(\mathrm{H}_{2} \mathrm{O}\right), 6.3\right.$; water content $(\mathrm{w} / \mathrm{w}), 35.2 \%$; total carbon, $5.0 \%$; total nitrogen, $<0.3 \%$ ]; soil $N$ (Naive soil) was collected from a field that had never been sprayed with MEP and other organophosphorus compounds $\left[\mathrm{pH}\left(\mathrm{H}_{2} \mathrm{O}\right)\right.$, 6.6; water content $(\mathrm{w} / \mathrm{w}), 33.7 \%$; total carbon, $4.4 \%$; total nitrogen, $<0.3 \%$ ]. Characterization of these soil samples is summarized in Table S1. Each soil was passed through a $2 \mathrm{~mm}$ sieve to remove large organic litters like leaves and roots.

\section{INSECTICIDE-SPRAYING EXPERIMENTS}

Experimental design of the insecticide-spraying test is shown in Figure S1. Approximately $150 \mathrm{~g}$ (dry weight) of each of the sieved soils were transferred into plastic pots $(10 \times 8 \mathrm{~cm}$; opening diameter $\times$ depth). The potted soils were incubated at $25^{\circ} \mathrm{C}$ with weekly application of MEP solution (diluted by distilled water) at a specific loading of $50 \mathrm{mg} \mathrm{kg}^{-1}$-dry soil (Tago et al., 2006). For both soils $\mathrm{S}$ and $\mathrm{N}$, duplicate runs (pot 1 and pot 2) were prepared and individually subjected to experiments and further analyses. Control treatments were conducted under the same conditions, but the addition of MEP solution was replaced by equal amount of distilled water only once a week. These pots were covered with a sheet of aluminum foil during incubation to prevent water evaporation and photodegradation of MEP. Soil samples from the surface layer up to a depth of $1 \mathrm{~cm}$ were collected 1 week after the final spraying, e.g., soil samples treated three times with MEP were collected 1 week after the 3rd MEP-spraying (see Figure $\mathrm{S} 1$ ), and then subjected to the various analyses described below.

\section{CFU COUNTING OF MEP-DEGRADING BACTERIA}

The total CFU (colony forming units) counts of MEP-degrading bacteria was measured by plating serial dilutions of soil samples $[1 \%(\mathrm{w} / \mathrm{w})$ diluted in distilled water] on $1.5 \%$ agar plates of MEP medium [0.08\% MEP, $20 \mathrm{mM}$ potassium phosphate $(\mathrm{pH}$ 7.0), $0.1 \%\left(\mathrm{NH}_{4}\right)_{2} \mathrm{SO}_{4}, 0.02 \% \mathrm{NaCl}, 0.01 \% \mathrm{MgSO}_{4} \cdot 7 \mathrm{H}_{2} \mathrm{O}, 0.05 \%$ $\mathrm{CaCl}_{2} \cdot 2 \mathrm{H}_{2} \mathrm{O}, 0.0002 \% \mathrm{FeSO}_{4} \cdot 7 \mathrm{H}_{2} \mathrm{O}, 0.1 \%$ yeast extract] and incubated for 4 days at $25^{\circ} \mathrm{C}$, as previously described (Tago et al., 2006). The CFU of MEP-degrading bacteria were determined by counting the colonies with a halo on the MEP plates. In the haloforming assay, the bacteria that are capable of degrading MEP to 3-methyl-4-nitrophenol were detected.

\section{ISOLATION AND IDENTIFICATION OF MEP-DEGRADING BACTERIA}

Isolated colonies were identified based on the partial sequences (c.a. $600 \mathrm{bp}$ ) of their $16 \mathrm{~S}$ rRNA genes. During isolation, each of the colonies was picked with a sterile toothpick and then suspended in $35 \mu \mathrm{l}$ TE buffer [ $10 \mathrm{mM}$ Tris-HCl, $1 \mathrm{mM}$ EDTA $(\mathrm{pH}$ 8.0)] in each well of a 96 well titer plate. The cells were subjected to heat shock treatment $\left(98^{\circ} \mathrm{C}\right.$ for $\left.3 \mathrm{~min}\right)$ in order to extract the genomic DNA, which was used as template for PCR amplification. The PCR amplification of bacterial 16S rRNA gene was performed with the use of a KOD Fx 
Neo polymerase (TOYOBO, Tokyo, Japan), a universal primer set, 16SA1 [5'-AGAGTTTGATCMTGGCTCAG-3'] and 16SB1 [5'-TACGGYTACCTTGTTACGACTT-3'] (Fukatsu and Nikoh, 1998), and the template DNA extracted as described above. The temperature program for PCR is as follows: $94^{\circ} \mathrm{C}$ for $2 \mathrm{~min}$, followed by 20 cycles of $98^{\circ} \mathrm{C}$ for $10 \mathrm{~s}, 55^{\circ} \mathrm{C}$ for $30 \mathrm{~s}$, and $68^{\circ} \mathrm{C}$ for $90 \mathrm{~s}$. The resulting $1.5 \mathrm{~kb}$ amplicons were used as templates of sequencing reaction conducted with a universal primer 357F [5'-CCTACGGGAGGCAGCAG-3'] (Muyzer et al., 1993). Taxonomic assignment of the resulting sequences was double checked by the RDP multiclassifier ver. 1.1 (Wang et al., 2007) and BLASTN-search (http://ncbi.nlm.nih.gov/blast/) against GreenGene database (DeSantis et al., 2006).

\section{DEEP SEOUENCING}

DNA was extracted from soil $\mathrm{S}$ and soil $\mathrm{N}$ samples before treatment (S0, N0), after the 2nd (S2) and 3rd (S3, N3) MEP-treatments, and after the 3rd control treatment (S3C, $\mathrm{N} 3 \mathrm{C}$ ) by using a slightly modified published protocol (Noll et al., 2005). Briefly, $0.5 \mathrm{~g}$ wet soil was combined with $0.08 \mathrm{~g}$ skim milk, $700 \mu l$ extraction buffer $[50 \mathrm{mM}$ Tris- $\mathrm{HCl}(\mathrm{pH}$ 8.0), $1.7 \%$ Polyvinylpyrrolidone, $\left.20 \mathrm{mM} \mathrm{MgCl}_{2}\right]$, and $0.5 \mathrm{ml}$ zirconia/silica beads $(0.1 \mathrm{~mm}$ diameter, Biospec, OK, USA), and blended in a Multi-Beads Shocker (Yasui Kikai, Osaka, Japan) at $2000 \mathrm{rpm}$ for $60 \mathrm{~s}$. Crude extracts were purified by phenol/chloroform/isoamyl alcohol (25:24:1) treatment followed by isopropanol precipitation. Contaminating RNA was digested with Ribonuclease (Nippon Gene, Toyama, Japan). The prepared DNA was subjected to PCR amplification of $16 \mathrm{~S}$ rRNA gene for deep sequencing. The variable region (V4) of bacterial 16S rRNA gene was amplified using universal primers 515F [5'-GTGCCAGCMGCCGCGGTAA-3'] and 806R [5'-GGACTACHVGGGTWTCTAAT-3'] (Caporaso et al., 2012). The PCR reaction mixture comprised of $50 \mu \mathrm{M}$ each dNTP, $0.4 \mu \mathrm{M} 515 \mathrm{~F}$ with Illumina P5 sequences, $0.4 \mu \mathrm{M} 806 \mathrm{R}$ with 6bases indexes and Illumina P7 sequences (Caporaso et al., 2012) (Illumina, San Diego, CA, USA), Q5 High-Fidelity DNA polymerase with Q5 reaction buffer (New England BioLabs, Ipswich, MA, USA) and the extracted soil DNA template. The PCR conditions were as follows: initial denaturation at $98^{\circ} \mathrm{C}$ for $90 \mathrm{~s}$, followed by 25 cycles of $98^{\circ} \mathrm{C}$ for $10 \mathrm{~s}, 54^{\circ} \mathrm{C}$ for $30 \mathrm{~s}, 72^{\circ} \mathrm{C}$ for $30 \mathrm{~s}$, and a final extension at $72^{\circ} \mathrm{C}$ for $2 \mathrm{~min}$. The PCR amplicons were purified as described previously (Itoh et al., 2014). DNA libraries containing all tagged-amplicons and internal control phiX were generated for paired-end sequencing by the MiSeq sequencer using MiSeq Reagent kit v2 (Illumina, San Diego, CA, USA) according to the manufacturer's instruction.

\section{QUANTITATIVE PCR}

Quantitative PCR (qPCR) of bacterial 16S rRNA gene was performed to amplify bacterial $16 \mathrm{~S}$ rRNA genes using a Power SYBR Green PCR Master Mix (Applied Biosystems, Foster City, CA, USA) and the LightCycler 96 System (Roche Applied Science, Indianapolis, IN, USA). The reaction mixture was comprised of $2 \times$ SYBR Green PCR Master Mix, $0.2 \mu \mathrm{M} 515 \mathrm{~F}$ and 806R primer pairs (Caporaso et al., 2012), $0.5 \mu \mathrm{g} / \mu \mathrm{l} \mathrm{BSA}$, and soil DNA as a template. The PCR conditions were as follows: initial denaturation at $95^{\circ} \mathrm{C}$ for $10 \mathrm{~min}$, followed by 45 cycles of $95^{\circ} \mathrm{C}$ for $30 \mathrm{~s}, 57^{\circ} \mathrm{C}$ for $30 \mathrm{~s}$, and $72^{\circ} \mathrm{C}$ for $30 \mathrm{~s}$. The amount of bacterial $16 \mathrm{~S}$ rRNA gene copies was calculated on the basis of the standard curve constructed using a dilution series of the target PCR product of Burkholderia sp. SFA1 (DDBJ accession no. AB232333).

\section{DATA ANALYSIS}

Internal control phiX sequences and low-quality sequences were removed, and paired sequences were joined as described previously (Itoh et al., 2014). Chimeric sequences were removed using uchime algorithm on Mothur program ver. 1.29.2 (Schloss et al., 2009) through the alignment with Greengene database (DeSantis et al., 2006). The resulting sequences were subjected to taxonomic assignment by using RDP multiclassifier ver. 1.1 (Wang et al., 2007 ) with an $80 \%$ confidence threshold. Operational taxonomic units (OTU) based analyses, including estimation of diversity indices and Principal Coordinate Analysis (PCoA) based on OTUs with $3 \%$ differences, were performed by using the macqiime ver. 1.6.0 (Caporaso et al., 2010). Phylogenetic tree was constructed by the neighbor-joining method with the bootstrap test (1000 replicates) under MEGA ver. 4.0.2 (Tamura et al., 2007). Analysis of variance (ANOVA) was performed using $\mathrm{R}$ software ver. 3.0.1 ( $\mathrm{R}$ Development Core Team, 2008) to analyze differences in $\mathrm{qPCR}$ data among samples.

\section{NUCLEOTIDE SEOUENCE ACCESSION NUMBER}

The nucleotide sequences reported in this study were deposited in the DDBJ/Genbank/EBI databases under the accession numbers: AB904935-AB905196 (16S rRNA gene sequences of isolates, Table S2) and the MG-RAST database (http://metagenomics.anl. gov/, Meyer et al., 2008) as a "Microbial succession under MEPspraying in 2012" project under the ID: 4562358.3-4562369.3 (deep sequencing, Table 1).

\section{RESULTS POPULATION DYNAMICS OF MEP-DEGRADING BACTERIA IN MEP-SPRAYED SOILS}

Abundance changes of MEP-degrading strains by a culturedependent method were investigated using two types of soils with different MEP-spraying histories: MEP-sprayed "soil S" and MEP-naive "soil N" (Table S1). Although the CFU of MEPdegrading bacteria were below the detectable level $\left(<10^{3} \mathrm{cfu}\right.$ $\mathrm{g}^{-1}$ dry soil) even 1 week after the insecticide application, they became detectable after the 2nd and 3rd treatments in soil S and soil N, respectively, (Figure 1). In the control, with only the addition of distilled water, no MEP-degraders were detected even after the 3rd treatment (Figure 1). These results indicate that the repeated spraying of MEP acts as a strong selective pressure on soil microbiota, confirming our findings from previous studies (Tago et al., 2006; Kikuchi et al., 2012). It has also been reported that some bacteria are capable of utilizing MEP as a sole carbon source, fostering their population increase (Hayatsu et al., 2000; Tago et al., 2006; Zhang et al., 2006; Kim et al., 2009), which likely explains the aboveobserved population dynamics of MEP-degrading strains in soil environments. 
Table 1 | Summary of deep sequencing and qPCR.

\begin{tabular}{|c|c|c|c|c|c|c|c|c|c|c|}
\hline Soil & $\begin{array}{c}\text { No. of } \\
\text { spraying }\end{array}$ & Pot No. & $\begin{array}{l}\text { Libarary } \\
\text { ID }\end{array}$ & $\begin{array}{c}\text { No. of } \\
\text { sequences }^{b}\end{array}$ & $\begin{array}{l}\text { No. of } \\
\text { OTU }_{0.03}^{c}\end{array}$ & $C x^{d}$ & \multicolumn{3}{|c|}{ Diversity indices $^{e}$} & $\begin{array}{l}\text { No. of } \\
\text { copies }^{f}\end{array}$ \\
\hline S & 2 & 1 & S2p1 & 13,346 & 796 & 0.99 & $1,188 \pm 103$ & $5.9 \pm 0.03$ & $15 \pm 0.3$ & $4.5 \pm 0.3 \times 10^{8}$ \\
\hline S & 3 & 1 & S3p1 & 14,600 & 575 & 0.99 & $813 \pm 79$ & $3.86 \pm 0.05$ & $4.5 \pm 0.1$ & $4.7 \pm 0.2 \times 10^{8}$ \\
\hline S & 0 & 2 & sop2 & 6,218 & 1,062 & 0.93 & $2,446 \pm 78$ & $8.62 \pm 0.01$ & $109 \pm 0.7$ & $4.6 \pm 0.2 \times 10^{8}$ \\
\hline S & 3 & 2 & S3p2 & 8,213 & 897 & 0.96 & $1,731 \pm 100$ & $6.43 \pm 0.03$ & $13 \pm 0.3$ & $4.4 \pm 0.5 \times 10^{8}$ \\
\hline S & $0^{\mathrm{a}}$ & control & $\mathrm{S} 3 \mathrm{C}$ & 17,933 & 1,533 & 0.94 & $2,260 \pm 123$ & $8.6 \pm 0.04$ & $124 \pm 2.8$ & $4.8 \pm 1.2 \times 10^{8}$ \\
\hline N & 0 & 1 & Nop1 & 13,540 & 1,500 & 0.85 & $3,268 \pm 190$ & $9.07 \pm 0.04$ & $138 \pm 5.8$ & $5.5 \pm 1.8 \times 10^{8}$ \\
\hline N & 3 & 1 & N3p1 & 10,171 & 1,028 & 0.95 & $1,919 \pm 114$ & $7.3 \pm 0.03$ & $36 \pm 0.8$ & $6.3 \pm 0.9 \times 10^{8}$ \\
\hline N & 0 & 2 & Nop2 & 15,054 & 1,747 & 0.87 & $3,655 \pm 180$ & $9.1 \pm 0.02$ & $151 \pm 3.4$ & $6.3 \pm 0.2 \times 10^{8}$ \\
\hline
\end{tabular}

${ }^{a}$ Control pots received distilled water (DW) once a week: soils were collected 1 week after 3rd DW-spraying.

${ }^{b}$ Number of sequences after removal of low-quality, chimeric, and archaeal sequences.

${ }^{c}$ Clustered at the $3 \%$ distance level.

${ }^{d}$ Calculated from the equation, $C X=1-(n / N)$, where " $n$ " is the number of OTUs composed of only one sequence (singleton) and $N$ is the total number of sequences. ${ }^{e}$ Each index was calculated based on the same amount of sequences (5174) sub-sampled from original libraries (Mean \pm SDs of 10 time sub-samplings is shown).

${ }^{f}$ Copy numbers (copies $g^{-1}$-dry soil) of $16 S$ rRNA genes estimated by qPCR (Mean \pm SDs of three time measurements of the same DNA sample is shown). Analysis of variance (ANOVA) was performed using $R$ software ver. 3.0.1 (R Development Core Team, 2008), showing the copy numbers were not significantly different between samples that were originated from the same field soil.
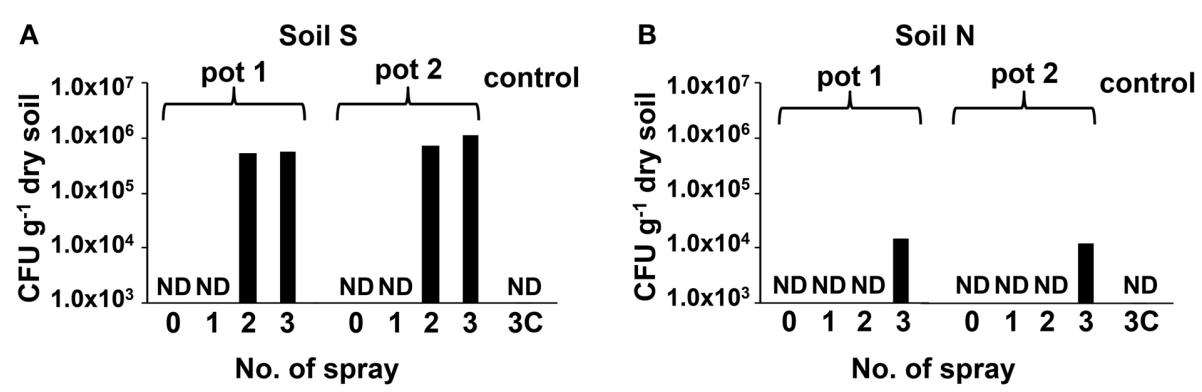

FIGURE 1 | Transition of CFU of MEP-degrading bacteria in MEP-sprayed soils. CFU of MEP-degrading bacteria in soil S (A) and soil N (B) were counted by using MEP medium plates. Results of replicated experiments (pot 1 and pot 2$)$ are shown. ND, not detected $\left(<1.0 \times 10^{3}\right.$ cfu g g $^{-1}$-dry soil).

\section{ISOLATION AND IDENTIFICATION OF MEP-DEGRADING BACTERIA}

From the soil S after the 2nd and 3rd MEP-treatments (S2 and S3), and soil $\mathrm{N}$ after the 3rd MEP-treatment (N3), colonies of the MEP-degrading bacteria were isolated and identified based on the partial sequences of $16 \mathrm{~S}$ rRNA gene. The sequence analyses demonstrated that the majority belonged to the betaproteobacterial genus Burkholderia. Specifically, they occupied around 97.9, 96.9, and $61.1 \%$ of the total sequenced-bacteria isolated from the S2, S3, and N3 soils, respectively, (Figure 2; Table S2). Notably, in contrast to the predominance of Burkholderia strains in the S2 and S3 samples, MEP-degraders from the N3 sample were more phylogenetically diverse with the presence of strains from the genera Dyella, Ralstonia, Pandoraea, Achromobacter, and Cupriavidus.

\section{SUCCESSION OF MICROBIOTA IN MEP-SPRAYED SOILS AS REVEALED BY DEEP SEQUENCING}

For comprehensive understanding of the temporal dynamics of microbiota in the MEP-sprayed soils, we performed deep sequencing of bacterial 16S rRNA genes from both soils before treatment (S0 and N0), after the 2nd (S2) and 3rd (S3 and N3) MEP-treatments, and after the 3rd control-treatment (S3C and N3C). The sequencing of PCR amplicons of partial 16S rRNA genes produced $>2 \times 10^{5}$ sequences in total (Table 1 ). The qPCR data showed that the amount of bacterial $16 \mathrm{~S}$ rRNA genes was stable at around $4 \times 10^{8}$ and $6 \times 10^{8} \mathrm{~g}^{-1}$-dry soil in soil $\mathrm{S}$ and soil $\mathrm{N}$, respectively, during the treatments (Table 1). Meanwhile, in both soils $\mathrm{S}$ and $\mathrm{N}$, diversity indices, chao1, Shannon, and reciprocal simpson decreased after MEP-spraying (Table 1), suggesting 


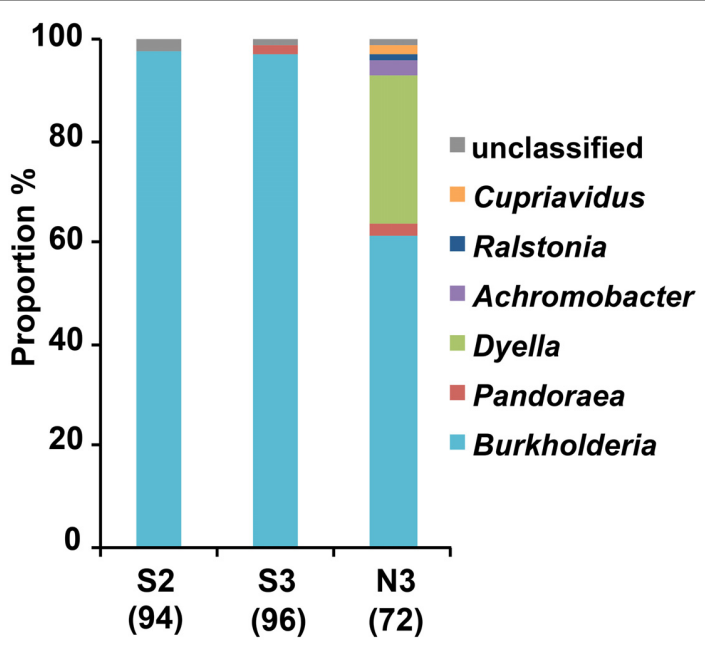

FIGURE 2 | Genus-level compositions of MEP-degrading bacteria isolated from MEP-sprayed soils. MEP-degrading isolates from soil $\mathrm{S}$ after two times and three times MEP spraying (S2 and S3, respectively) and from soil $\mathrm{N}$ after three times MEP spraying (N3) were identified by partial (c.a. $600 \mathrm{bp}$ ) sequencing of $16 \mathrm{~S}$ rRNA gene. Numbers in parentheses indicate total numbers of inspected MEP-degrading strains that were randomly selected from 2 pots in each soil (i.e., results of pots 1 and 2 are merged here). Sequences were subjected to taxonomic assignment by using RDP multiclassifier with a threshold level of $80 \%$.

that MEP treatment caused the decrease of soil microbial diversity.

Similarities among the sequence libraries of each soil sample were analyzed by PCoA based on weighted unifrac distance (Figure S2). The results suggest that the bacterial compositions of S2, S3, and N3 were distinct from those of S0 and N0 samples, although the shift direction was different between the soil $\mathrm{S}$ and soil N. The controls, S3C and N3C, were closely related to the soils before treatments, S0 and N0. These results also clearly demonstrate that MEP-spraying dramatically altered the community structure of soil microbiota.

\section{BACTERIAL GROUPS RESPONDING TO MEP-SPRAYING}

Figures 3A,B show the phylum-level (class-level in the Proteobacteria) distribution of sequences obtained from the deep sequence libraries. Among the diverse bacterial groups, Betaproteobacteria drastically increased after MEP-spraying in all samples from both soils S and N. Especially in soil S, the relative abundance of Betaproteobacteria was over $40 \%$ ( $80.4 \%$ in pot 1 and $49.8 \%$ in pot 2 ) after the 3rd MEP-treatment (Figure 3A). In the control samples ( $33 \mathrm{C}$ and $\mathrm{N} 3 \mathrm{C}$ ), the bacterial composition appeared to be stable based from the initial states ( $\mathrm{S} 0$ and $\mathrm{N} 0$ ), as also supported by the PCoA profile (Figure S2).

Within the increasing community of Betaproteobacteria, the genus Burkholderia was the most abundant, followed by Ralstonia and Pandoraea (Figures 3C,D). Before MEP treatment, few Burkholderia sequences were detected. However, after the 3rd treatment, the frequencies of Burkholderia drastically increased up to $53.8 \%$ in soil S pot $1,41.1 \%$ in soil S pot $2,55.7 \%$ in soil $\mathrm{N}$ pot 1 , and $66.9 \%$ in soil $\mathrm{N}$ pot 2 .
Figure 4 shows increase in the relative proportion of specific bacteria genera during the MEP-spraying experiments. It depicts the top 10 genera with the higher frequency after the 3rd treatment. From the list, the Burkholderia, Cupriavidus, Pseudomonas, and Arthrobacter are already well-known MEPdegrading strains (Tago et al., 2006; Zhang et al., 2006; Kim et al., 2009). Furthermore, the genera Pandoraea, Ralstonia, and Dyella, which were additionally identified earlier as MEPdegrading group (Figure 2), were also included in the top 10 genera that highly responded to MEP (Figure 4). In both soils $\mathrm{S}$ and $\mathrm{N}$, the frequencies of Burkholderia and Ralstonia drastically increased in response to MEP-spraying at two to three orders of magnitude, suggesting that these genera might possess a strong MEP-assimilation ability to highly adapt to the biological niche resulting from MEP-sprayed soils. Other bacterial groups, such as Rhodanobacter, Nevskia, and Methylobacillus, were also included in the top 10 (Figure 4), although they were not detected through the culture-dependent approach (Figure 2). These strains might assimilate the intermediates of MEP degradation such as 3-methl4-nitrophenol and p-nitrophenol (Hayatsu et al., 2000; Arora et al., 2013), and thus proliferate under the MEP treatment. The frequencies of these bacterial groups with high increasing ratios after MEP treatment were almost stable in the control set-ups in both of soils $\mathrm{S}$ and $\mathrm{N}$ (Fold: 0.2 3.4), emphasizing that these bacteria respond to MEP-spraying.

\section{BURKHOLDERIA STRAINS RESPONDING TO MEP-SPRAYING}

To clarify the diversity of Burkholderia strains in the MEP-sprayed soils, 16S rRNA gene sequences of Burkholderia derived from the MEP-degrading isolates and the deep sequencing libraries of the soils treated with MEP three times (i.e., S3 and N3 soils) were classified into OTUs defined by $100 \%$ sequence identity. In the MEP-degrading isolates, 4 and 8 OTUs were identified from the S3 and N3 soils, respectively, in which a single and distinct OTU dominantly occupied at $>70-90 \%$ frequency (Figures 5A,B). Although $>100$ OTUs were determined from all of the S3p1, S3p2, N3p1, and N3p2 libraries, a single and distinct OTU was dominant with $>40 \%$ frequency in each soil sample (Figures 5C-F). In sequence libraries of both soil S and soil N, the dominant OTUs were not detected or a few sequences were detected before the MEP-treatment (Figure S3). These culturedependent and -independent studies strikingly demonstrated that a particular phylotype of Burkholderia dominantly responds in soil environments in the presence of MEP.

We then estimated the phylogenetic relationship of these dominant Burkholderia strains based on 255 bp sequences of the V4 region of $16 \mathrm{~S}$ rRNA gene (Figure 6). Regardless of whether the strain was identified by the culture-dependent or -independent method, each of the dominant Burkholderia OTUs derived from isolates and deep sequences was clustered together with the OTUs detected from the soil of the same origin (Figure 6), strongly indicating that our isolates are representative strains of MEPdegrading Burkholderia dominating the MEP-sprayed soils. This also indicates that the Burkholderia frequently detected from deep sequencing in MEP-sprayed soils are most likely to have MEP-degrading activity. The most dominant OTUs in soil S samples were related to pathogenic Burkholderia such as B. cepacia, 

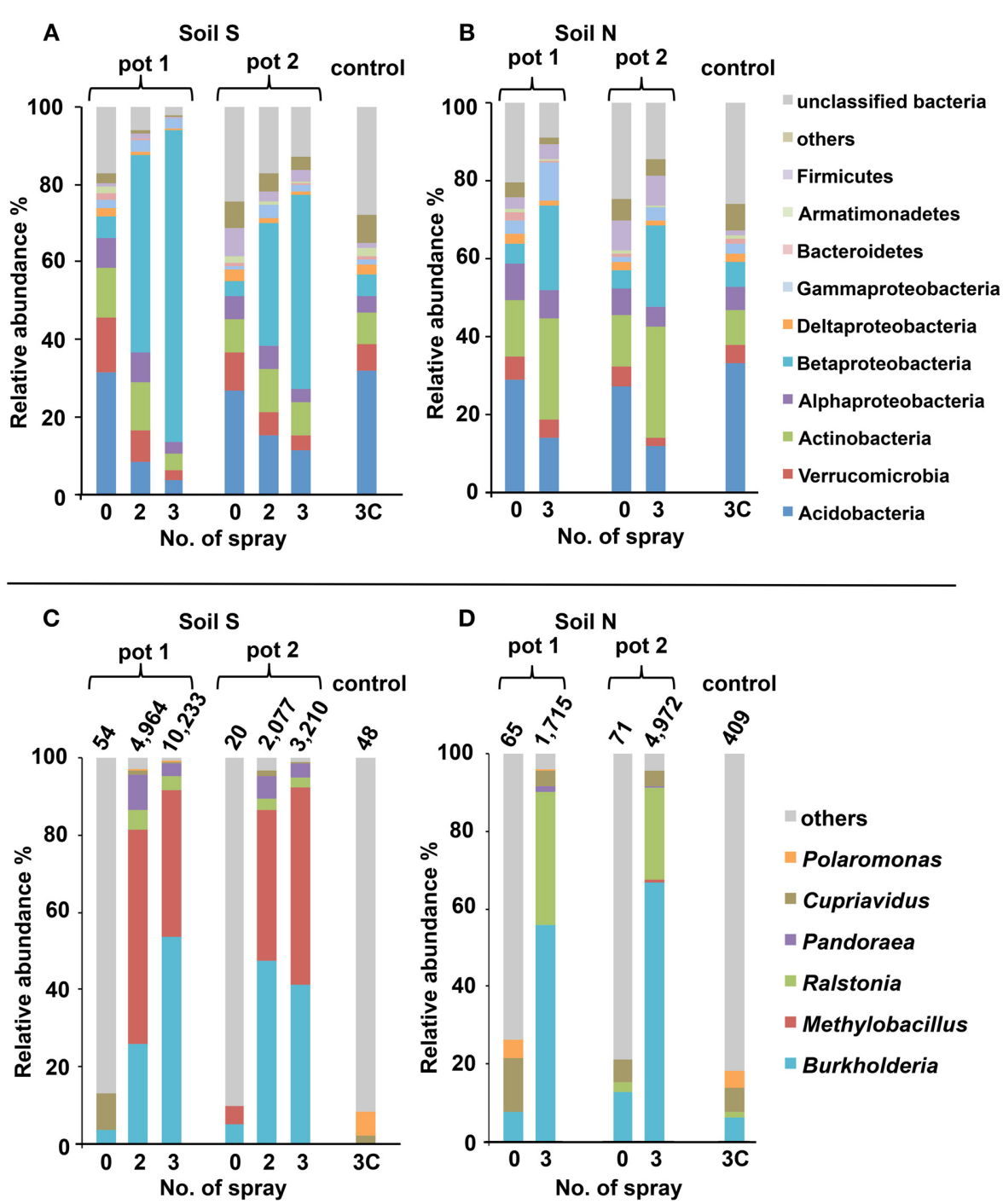

FIGURE 3 | Structural changes of microbial communities in MEP-sprayed soils. Soil $S(\mathbf{A}, \mathbf{C})$ and soil $N(\mathbf{B}, \mathbf{D})$ were analyzed by deep sequencing of $16 \mathrm{~S}$ rRNA gene. For each soil, results of replicated experiments (pot 1 and pot 2) are shown. Relative distributions of the sequences at $(\mathbf{A}, \mathbf{B})$ phylum-level (class-level in the Proteobacteria) and
(C,D) genus-level within Betaproteobacteria are shown. In (C,D), total numbers of betaproteobacterial sequences excluding those of unclassified genus are depicted on the bars. Sequences were subjected to taxonomic assignment by using RDP multiclassifier with a threshold level of $80 \%$.
B. glumae, and B. pseudomallei of the Burkholderia cepacia complex (Bcc) group (Coenye et al., 2001), while those in soil N samples were related to known MEP-degrading bacteria isolated from soils and symbiotic Burkholderia in stinkbugs (Tago et al., 2006; Kikuchi et al., 2011). These results suggest that the phylogenic lineage of Burkholderia responding to MEP-spraying appears likely to not be general, but specific for each soil environment.

\section{DISCUSSION}

\section{EFFECTS OF FIELD-USE HISTORY ON SOIL MICROBIOTA RESPONDING TO MEP TREATMENT}

Deep sequencing combined with culture-dependent approach clearly demonstrated that soil microbiota is strongly affected by the application of MEP, and furthermore, bacterial communities responding to MEP-spraying were remarkably different between the two andisol soils (soil S and soil N) (Figures 3, 4, 6 and Figure S2) despite their almost similar origin and chemical properties (Table S1). Notably, the two soils have different histories of insecticide application: the agricultural field where soil S was obtained had experienced at least 4 years of MEP spraying; the field where soil $\mathrm{N}$ was collected was not subjected to such insecticide application (Table S1). Therefore, in soil S, MEP-degrading bacteria (i.e., Burkholderia species) might already exist at a certain level, thus allowing them to respond quickly to the presence of the chemical. Meanwhile, the greater variety of MEP-degrading bacteria in soil $\mathrm{N}$ may be due to the absence of selection pressure from MEP. Although the enhanced biodegradation caused by repeated treatment with the same insecticide were reported from the 1970 s 

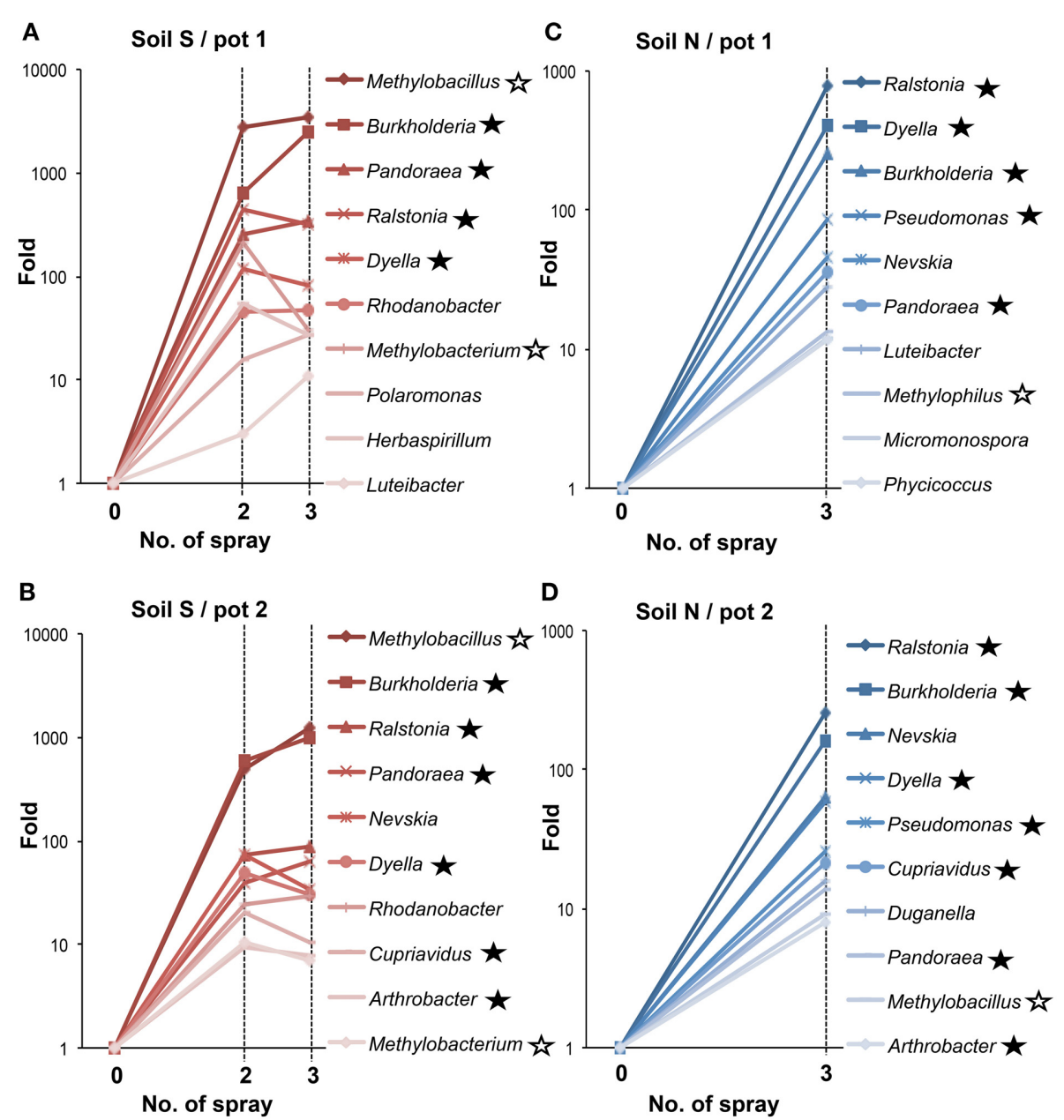

FIGURE 4 | Temporal changes of relative proportions of bacterial genera during MEP-spraying. (A,B) Soil S; $(\mathbf{C}, \mathbf{D})$ soil N. Relative proportions of bacterial genera were estimated based on the read numbers of deep sequencing of $16 \mathrm{~S}$ rRNA sequences. Closed asterisks indicate the genera, which have been reported to degrade MEP (Tago et al., 2006; Zhang et al., 2006; Kim et al., 2009), or are newly identified as MEP-degrading bacteria in this study (Figure 2). Open asterisks indicate methylotrophs. In addition to the relative increasing rates in MEP-sprayed soils, those in DW-sprayed soils (controls) are shown in text.
(Felsot, 1989), little is known about the relation between soil microbial succession/adaptation and insecticide-spraying history. This is the first report to show the different microbial-community responses against insecticide re-treatment in soils that previously experienced such chemical application vs. naive soil with no such treatment prior to the experiment.

It should be noted that the bacterial composition of the initial states in both soils $\mathrm{S}$ and $\mathrm{N}$ was similar to each other (Figure S2) despite their different MEP-spraying history. This result strongly suggests that, although speculative, microbial community-structure disturbed by insecticide-spraying could recover to an initial community composition once the insecticide application is terminated. To clarify the plasticity of microbial community in more detail, it would be of great interest to investigate succession process of insecticide-enriched microbiota after terminating insecticide spraying. Interestingly, our results demonstrated that soil diagnostics of biological activity should not be inferred only based on a snapshot of environmental microbial community. To estimate potentials of a soil (microbiota) more precisely, it may be more important to trace the microbial succession under environmental stimuli.

\section{BURKHOLDERIA IS A KEY PLAYER IN MEP-DEGRADATION}

Among the bacterial groups that dominantly responded to this insecticide, the genus Burkholderia was the most abundant after MEP-treatment (Figures 3C,D) and included a number of MEPdegrading isolates (Figure 2). Previous studies from China, Japan, and South Korea that were based on culture-dependent methods have repeatedly isolated MEP-degrading Burkholderia strains from MEP-contaminated soils at a higher frequency relative to other genera (Tago et al., 2006; Zhang et al., 2006; Kim et al., 2009). Taken together, our findings from both culture-dependent and -independent approaches strongly suggest that Burkholderia is a key bacterial group for MEP-degradation in soil environments. Remarkably, Burkholderia species were also found to degrade other organophosphorus insecticides, which includes 


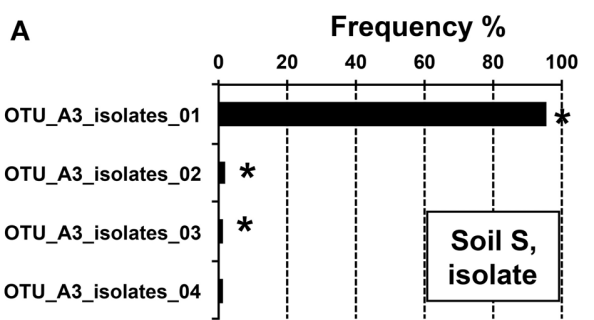

C

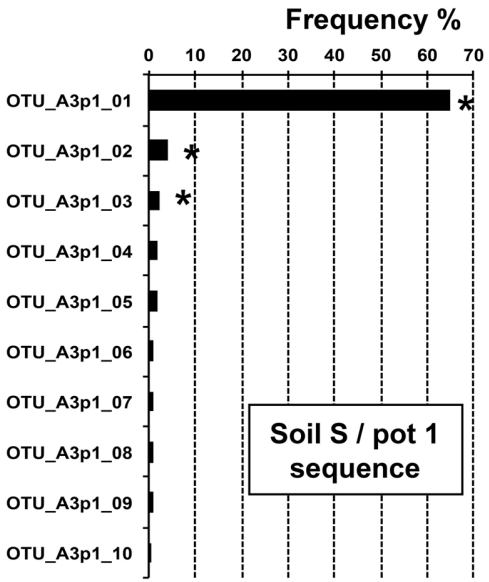

E

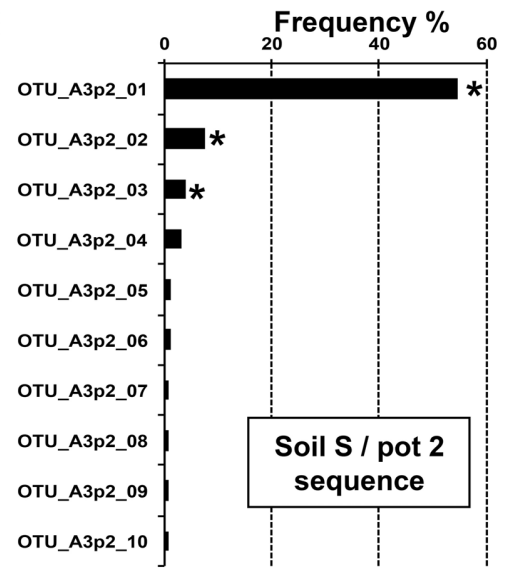

FIGURE 5 | Relative abundance of Burkholderia OTUs in MEP-sprayed soils. Relative abundance of $16 \mathrm{~S}$ rRNA gene sequences assigned to different OTUs (100\% sequence identity thresholds) of the genus

Burkholderia in the MEP-degrading isolates $(\mathbf{A}, \mathbf{B})$ and the deep sequence
B $\quad$ Frequency $\%$

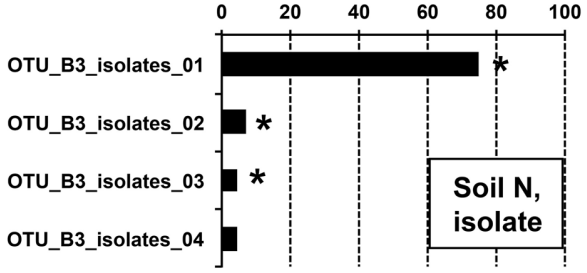

D

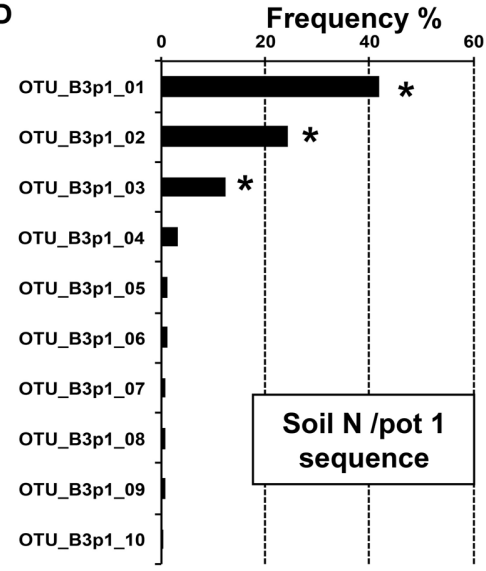

$\mathbf{F}$

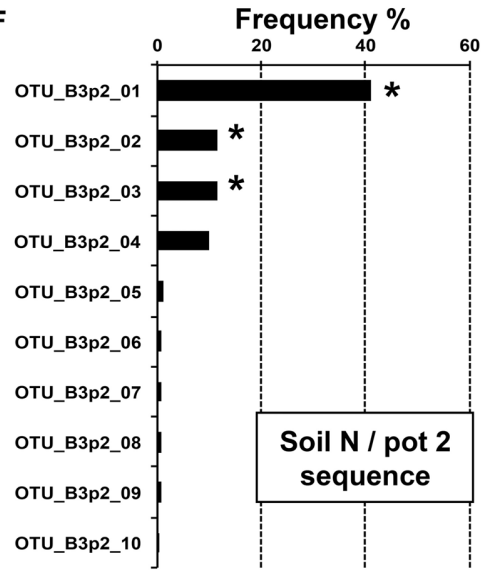

libraries (C-F). (A,C,E) Soil S; (B,D,F) soil N. Data showed the top 4 or 10 OTUs with high frequency in Burkholderia isolates or sequences, respectively. OTUs with asterisks were subjected to phylogenetic analysis (see Figure 6). parathion, methyl parathion, glyphosate, and chlorpyrifosmethyl (Keprasertsupa et al., 2001; Kuklinsky-Sobral et al., 2005; Kim et al., 2007b, 2009). Considering that MEP-degrading strains of Burkholderia frequently show cross-acclimation against other organophosphorus compounds (Hayatsu et al., 2000; Kim and Ahn, 2009; Kim et al., 2009; Kikuchi et al., 2012), Burkholderia might have a pivotal role in the degradation of various insecticides. To clarify this point, it would be of great interest to also employ a deep sequencing survey of 16S rRNA genes for various types of organophosphorus insecticide-contaminated soils.

\section{OTHER BACTERIAL GROUPS RESPONDING TO MEP-SPRAYING}

Previous studies have isolated and characterized MEP-degrading bacteria from genera Cupriavidus, Pseudomonas, Sphingomonas, Corynebacterium, Arthrobacter, and Burkholderia (Tago et al., 2006; Zhang et al., 2006; Kim et al., 2009). In addition to Burkholderia, members of genera Dyella, Ralstonia, Pandoraea, and Achromobacter were also isolated as MEP-degrading bacteria in our culture-dependent experiments (Figure 2). Hence, this is the first record of MEP-degrading strains from these four genera, suggesting that broader taxonomic groups could contribute to MEP-degradation in natural soil environments. Some 


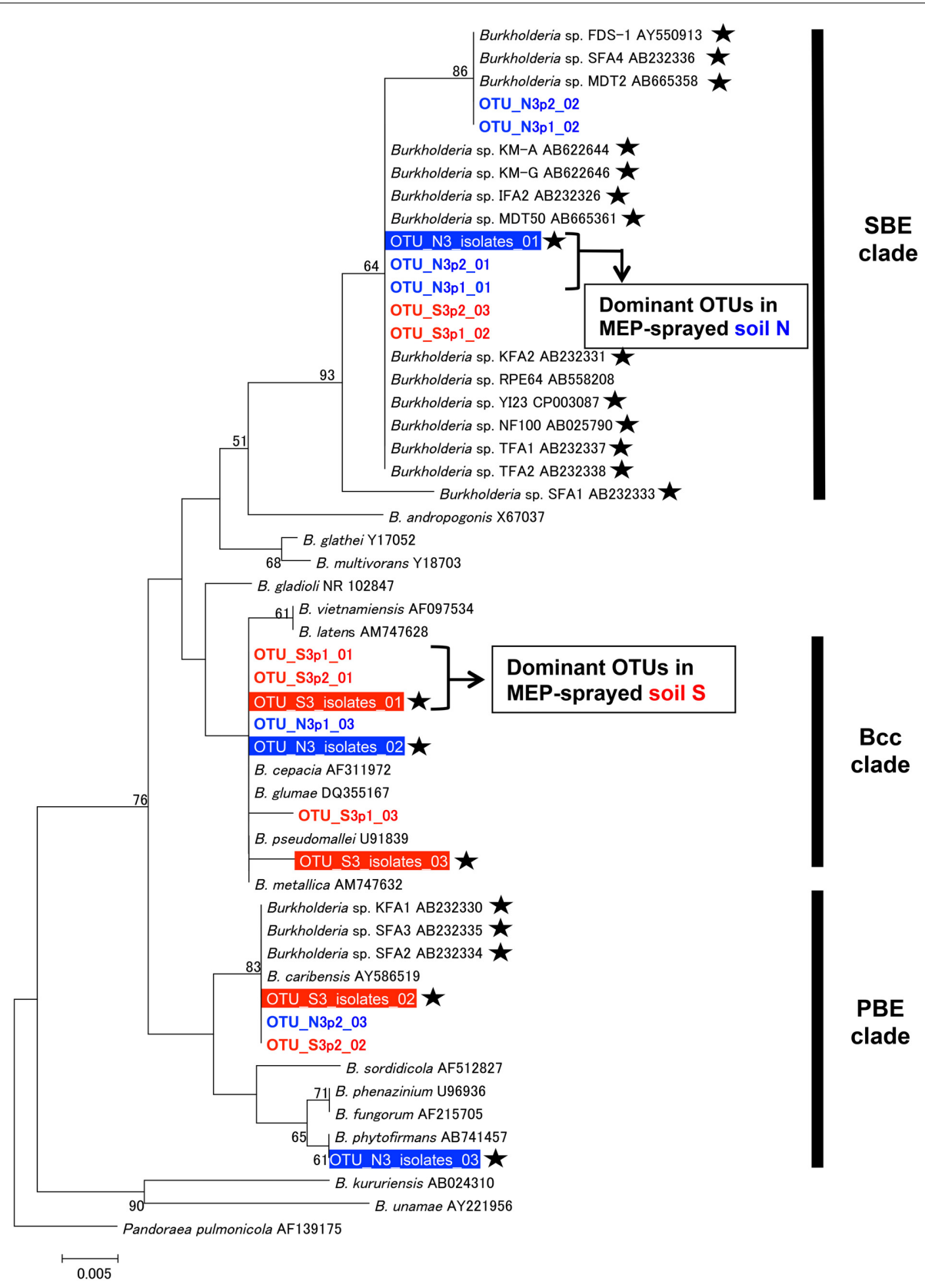

FIGURE 6 | Phylogenetic analysis of Burkholderia strains dominating in MEP-sprayed soils. A neighbor-joining tree inferred from aligned

$255 \mathrm{bp}$ sequences of $16 \mathrm{~S}$ rRNA gene is shown. Phylogenetic placements of OTUs (OTUs at $100 \%$ identity thresholds) of Burkholderia, identified from the MEP-degrading isolates and deep sequences, were estimated. Among dominant OTUs in each soil samples, top 3 OTUs (see Figure 5) were included in the analysis. Red and blue colored OTUs are detected from soil S and soil $N$, respectively. Outline letters on a filled background indicate OTUs determined by the isolation. Colored letters on a white background indicate OTUs detected by the deep sequencing. Asterisks indicate MEP-degrading Burkholderia strains. Clade names of SBE (stinkbug-associated beneficial and environmental group), Bcc (Burkholderia cepacia complex), and PBE (plant-associated beneficial and environmental group), respectively, according to Itoh et al. (2014), Coenye et al. (2001), and Suárez-Moreno et al. (2012), are shown on the right side. Bootstrap values higher than $50 \%$ are depicted at the nodes. The $16 \mathrm{~S}$ rRNA sequence of Pandoraea pulmonicola (AF139175) was used as an outgroup. strains of Ralstonia and Achromobacter have already been reported to degrade organophosphorus compounds that are analogous to MEP, particularly fenamifos (organophosphorus nematicide) and methyl parathion (organophosphorus insecticide), respectively, (Zhang et al., 2005; Cabrera et al., 2010). Similar to
Burkholderia strains, these bacteria probably have an ability for cross-acclimation toward other organophosphorus compounds.

In addition to the complete degradation of MEP by a single bacterium, the cooperative degradation of MEP has also been reported in vitro. In this case, MEP-hydrolyzing 
and MEP-hydrolysate-degrading bacteria cooperate for complete consumption of the chemical compound (Katsuyama et al., 2009). Previous studies have shown that some Burkholderia strains, though ineffective against MEP, are able to degrade its hydrolysate, 3-methyl-4-nitrophenol (Kim et al., 2007a; Katsuyama et al., 2009). Hence, some of the increasing bacteria identified by deep sequencing (Figure 4) from the MEPsprayed soils might be directly involved in the hydrolysis of MEP, while others might contribute to the degradation of the resulting hydrolysates. Such a synergistic interaction among bacterial species could promote efficient degradation of MEP in soils.

\section{METHYLOTROPHS COULD PLAY A ROLE IN MEP-DEGRADATION}

Notably, deep sequencing revealed that the frequency of Methylobacillus, Methylobacterium, and Methylophilus, which were never detected by the culture-dependent approach in this study and from previous researches (Tago et al., 2006; Zhang et al., 2006; Kim et al., 2009), also dramatically increased in soils after MEP-spraying (Figure 4). Most members of these genera are methylotrophic, that is, they actively use one-carbon compounds such as methanol as a sole carbon source (Kolb and Stacheter, 2013). Past studies have demonstrated that bacteria break down MEP into 3-methyl-4-nitrophenol and dimethyl phosphate during the initial hydrolysis step (Spillner et al., 1979; IPCS, 1992) (Figure 7). Though the succeeding stages for biodegrading the former aromatic compound have been described in detail (Spillner et al., 1979; IPCS, 1992; Hayatsu et al., 2000), the fate of dimethyl phosphate in soil still remains unclear. In the case of the degradation of paraoxon, an analog of MEP, the initial hydrolysis process produces diethyl phosphate, which is then further hydrolyzed into two molecules of ethanol by Delftia acidovorans and Pseudomonas putida through phosphodiesterase and phosphatase enzymes (Tehara and Keasling, 2003).
Although speculative, dimethyl phosphate may also be hydrolyzed into two molecules of methanol by a similar route during MEPdegradation. If so, the methylotrophs detected in this study may consume and utilize such generated methanol for growth (Figure 7).

It has been reported that accumulated methanol is harmful to organisms that are unable to metabolize it (Martin-Amat et al., 1978). In fact, growth of MEP-degrading Burkholderia strains isolated in this study was depressed by a tiny amount of methanol contamination (Figure S4). If methylotrophs rapidly consume any methanol generated during MEP-degradation, they might protect other bacteria involved in the overall degradation process from the toxicity of this by-product. This could probably lead to better growth of such relevant bacterial communities, thus contributing to more efficient and complete mineralization of MEP. This hypothesis could be verified through future evaluations on the (1) degradability of dimethyl phosphate by methylotrophs and (2) co-culture of MEP-degrading bacteria and methylotrophs.

\section{CONCLUDING REMARKS}

This study demonstrated the effect of MEP-spraying history to the microbial succession under MEP application and identified key bacteria for MEP-degradation by performing both culture experiments and high-throughput sequencing. Owing to the enormous information generated by the deep sequencing of bacterial 16S rRNA gene, we comprehensively revealed the community structures of bacterial species responding to MEP, and found previously unseen members, methylotrophs, that may play an important role in the complete degradation of MEP in soil environments. In contrast, it should be noted that the partial sequencing of $16 \mathrm{~S}$ rRNA gene gave us only indirect information about the MEP-degrading strains. In fact, our previous study

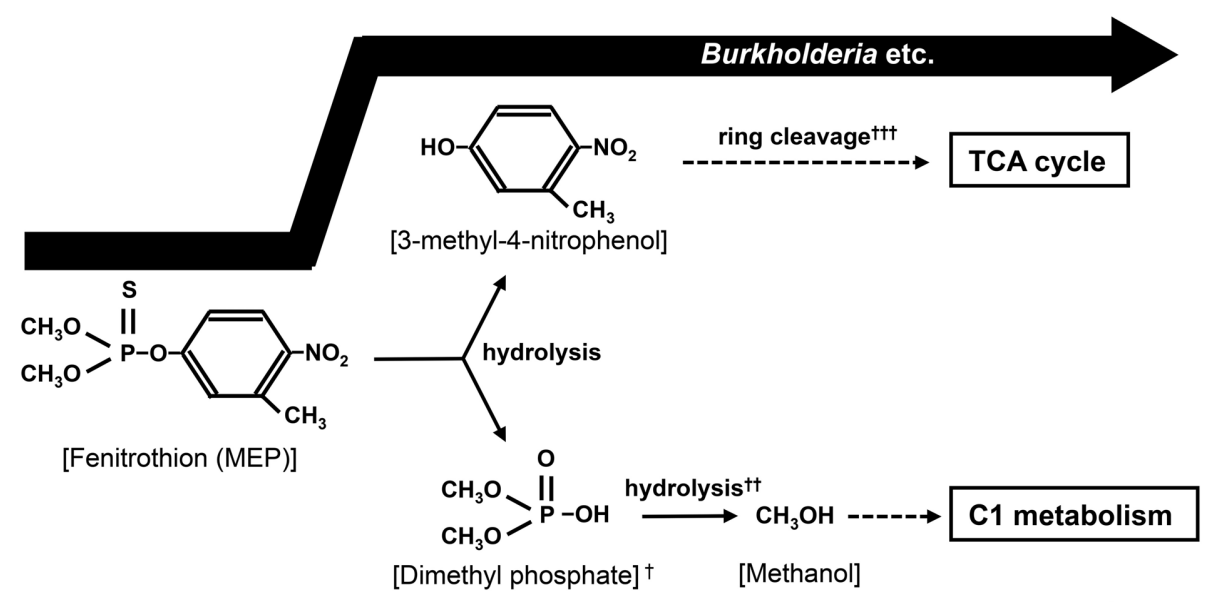

Methylotrophs

FIGURE 7 | Proposed biodegradation pathway of MEP. In addition to the utilization of 3-methyl-4-nitrophenole by Burkholderia and other bacteria, methanol generated from hydrolysis of dimethyl phosphate might be used as a carbon source by soil bacteria like methylotrophs. ${ }^{\dagger} \mathrm{P}=\mathrm{S}$ was rapidly substituted to $\mathrm{P}=\mathrm{O}$ by oxidation in environment (Bajgar, 2004; Karpouzas and Singh, 2006). ${ }^{\dagger \dagger}\left(\mathrm{CH}_{3} \mathrm{O}\right)_{2} \mathrm{POOH}+2 \mathrm{H}_{2} \mathrm{O} \rightarrow 2 \mathrm{CH}_{3} \mathrm{OH}+\mathrm{PO}_{4}^{3-}+3 \mathrm{H}^{+}$. ${ }^{+\dagger}$ The ring cleavage process has been reported in the biodegradation of MEP or MEP analog (Hayatsu et al., 2000; Zhang et al., 2006). 
reported that even Burkholderia strains exhibiting high (>99.8\%) sequence similarities in 16S rRNA gene possess quite different MEP-degrading activities (Kikuchi et al., 2012). Sequencing of functional genes involved in the MEP-degradation pathway might give more direct information for MEP-degradation in environmental soils, although MEP-degradation genes are not well understood (Singh, 2009). In addition, fungal biodegradation of MEP has been also reported (Baarschers and Heitland, 1986), although here we focused only on bacteria. Metagenomic approaches of functional genes and more comprehensive survey including fungal communities in soils should improve our knowledge of MEP-degradation by soil microorganisms.

\section{ACKNOWLEDGMENTS}

We appreciate Tomo Aoyagi and Natsuki Nakamura (AIST) for technical assistance, and Mia Terashima (Hokkaido University) for English correction. This study was supported by the Program for Promotion of Basic and Applied Researches for Innovations in Bio-oriented Industry, the Ministry of Education, Culture, Sports, Science and Technology (MEXT) KAKENHI Grant number 24117525, and Grant-in-Aid for Scientific Research (B).

\section{SUPPLEMENTARY MATERIAL}

The Supplementary Material for this article can be found online at: http://www.frontiersin.org/journal/10.3389/fmicb. 2014.00457/abstract

\section{REFERENCES}

Arbeli, Z., and Fuentes, L. C. (2007). Accelerated biodegradation of pesticides: an overview of the phenomenon, its basis and possible solutions; and a discussion on the tropical dimension. Crop Protect. 26, 1733-1746. doi: 10.1016/j.cropro. 2007.03.009

Arora, P. K., Srivastava, A., and Singh, V. P. (2013). Bacterial degradation of nitrophenols and their derivatives. J. Hazard. Mater. 266C, 42-59. doi: 10.1016/j.jhazmat.2013.12.011

Baarschers, H. W., and Heitland, S. H. (1986). Biodegradation of fenitrothion and fenitrooxon by the fungus Trichoderma viride. J. Agric. Food Chem. 34, 707-709. doi: 10.1021/jf00070a029

Bajgar, J. (2004). Organophosphates/nerve agent poisoning: mechanism of action, diagnosis, prophylaxis, and treatment. Adv. Clin. Chem. 38, 151-216. doi: 10.1016/S0065-2423(04)38006-6

Cabrera, J. A., Kurtz, A., Sikora, R. A., and Schouten, A. (2010). Isolation and characterization of fenamiphos degrading bacteria. Biodegradation 21, 1017-1027. doi: $10.1007 / \mathrm{s} 10532-010-9362-\mathrm{z}$

Caporaso, J. G., Kuczynski, J., Stombaugh, J., Bittinger, K., Bushman, F. D., Costello, E. K., et al. (2010). QIIME allows analysis of high-throughput community sequencing data. Nat. Methods 7, 335-336. doi: 10.1038/ nmeth.f.303

Caporaso, J. G., Lauber, C. L., Walters, W. A., Berg-Lyons, D., Huntley, J., Fierer, N., et al. (2012). Ultra-high-throughput microbial community analysis on the Illumina HiSeq and MiSeq platforms. ISME J. 6, 1621-1624. doi: 10.1038/ismej.2012.8

Coenye, T., Vandamme, P., Govan, J. R., and LiPuma, J. J. (2001). Taxonomy and identification of the Burkholderia cepacia complex. J. Clin. Microbiol. 39, 3427-3436. doi: 10.1128/JCM.39.10.3427-3436.2001

da Silva, N. A., Birolli, W. G., Seleghim, M. H. R., and Porto, A. L. M. (2013). "Biodegradation of the organophosphate pesticide profenofos by Marine Fungi," in Applied Bioremediation-Active and Passive Approaches, eds Y. B. Patil and P. Rao (Rijeka: InTechWeb), 149-180. doi: 10.5772/56372

DeSantis, T. Z., Hugenholtz, P., Larsen, N., Rojas, M., and Brodie, E. L. (2006). Greengenes, a chimera-checked $16 \mathrm{~S}$ rRNA gene database and workbench compatible with ARB. Appl. Environ. Microbiol. 72, 5069-5072. doi: 10.1128/AEM.03006-05
Diez, M. C. (2010). Biological aspects involved in the degradation of organic pollutants. J. Soil. Sci. Plant Nutr. 10, 244-267. doi: 10.4067/S0718-95162010000 100004

Fang, H., Cai, L., Yang, Y., Ju, F., Li, X., Yu, Y., et al. (2014). Metagenomic analysis reveals potential biodegradation pathways of persistent pesticides in freshwater and marine sediments. Sci. Total Environ. 1, 983-992. doi: 10.1016/j.scitotenv.2013.10.076

Felsot, A. S. (1989). Enhanced biodegradation of insecticides in soil: implications for agroecosystems. Ann. Rev. Entomol. 34, 453-476. doi: 10.1146/annurev.en.34.010189.002321

Fukatsu, T., and Nikoh, N. (1998). Two intracellular symbiotic bacteria from the mulberry psyllid Anomoneura mori (Insecta, Homoptera). Appl. Environ. Microbiol. 64, 3599-3606.

Hayatsu, M., Hirano, M., and Tokuda, S. (2000). Involvement of two plasmids in MEP degradation by Burkholderia sp. strain NF100. Appl. Environ. Microbiol. 66, 1737-1740. doi: 10.1128/AEM.66.4.1737-1740.2000

International Programme on Chemical Safety (IPCS). (1992). "Environmental health criteria 133: fenitrothion," in World Health Organization (Accessed December 22, 2013). http://www.inchem.org/documents/ehc/ehc/ehc133.htm

Itoh, H., Aita, M., Nagayama, A., Meng, X. Y., Kamagata, Y., Navarro, R., et al. (2014). Evidence of environmental and vertical transmission of Burkholderia symbionts in the oriental chinch bug Cavelerius saccharivorus (Heteroptera: Blissidae). Appl. Environ. Microbiol. doi: 10.1128/AEM.01087-14. (in press).

Jacobsen, C. S., and Hjelmsø, M. H. (2014). Agricultural soils, pesticides and microbial diversity. Curr. Opin. Biotech. 27, 15-20. doi: 10.1016/j.copbio.2013.09.003

Karpouzas, D. G., and Singh, B. K. (2006). Microbial degradation of organophosphorus xenobiotics: metabolic pathways and molecular basis. Adv. Microb. Physiol. 51, 119-185. doi: 10.1016/S0065-2911(06)51003-3

Katsuyama, C., Nakaoka, S., Takeuchi, Y., Tago, K., Hayatsu, M., and Kato, K. (2009). Complementary cooperation between two syntrophic bacteria in pesticide degradation. J. Theor. Biol. 256, 644-654. doi: 10.1016/j.jtbi.2008. 10.024

Keprasertsupa, C., Upathamb, E. S., Sukhapanthb, N., and Prempreed, P. (2001). Degradation of methyl parathion in an aqueous medium by soil Bacteria. Scienceasia 27, 261-270. doi: 10.2306/scienceasia1513-1874.2001.27.261

Kikuchi, Y., Hayatsu, M., Hosokawa, T., Nagayama, A., Tago, K., and Fukatsu, T. (2012). Symbiont-mediated insecticide resistance. Proc. Natl. Acad. Sci. U.S.A. 109, 8618-8622. doi: 10.1073/pnas. 1200231109

Kikuchi, Y., Hosokawa, T., and Fukatsu, T. (2011). An ancient but promiscuous host-symbiont association between Burkholderia gut symbionts and their heteropteran hosts. ISME J. 5, 446-460. doi: 10.1038/ismej.2010.150

Kim, J. R., and Ahn, Y. J. (2009). Identification and characterization of chlorpyrifosmethyl and 3,5,6-trichloro-2-pyridinol degrading Burkholderia sp. strain KR100. Biodegradation 20, 487-497. doi: 10.1007/s10532-008-9238-7

Kim, K. D., Ahn, J. H., Kim, T., Park, S. C., Seong, C. N., Song, H. G., et al. (2009). Genetic and phenotypic diversity of fenitrothion-degrading bacteria isolated from soils. J. Microbiol. Biotechnol. 19, 113-120. doi: 10.4014/jmb. 0808.467

Kim, S. H., Park, M. R., Han, S., Whang, K., Shim, J. H., and Kim, I. S. (2007a). Degradation of 3-Methyl-4-nitrophenol, a Main Product of the Insecticide Fenitrothion, by Burkholderia sp. SH-1 Isolated from Earthworm (Eisenia fetida) Intestine. J. Appl. Biol. Chem. 50, 281-287.

Kim, T., Ahn, J. H., Choi, M. K., Weon, H. Y., Kim, M. S., Seong, C. N., et al. (2007b). Cloning and expression of a parathion hydrolase gene from a soil bacterium, Burkholderia sp. JBA3. J. Microbiol. Biotechnol. 17, 1890-1893.

Kolb, S., and Stacheter, A. (2013). Prerequisites for amplicon pyrosequencing of microbial methanol utilizers in the environment. Front. Microbiol. 4:268. doi: $10.3389 /$ fmicb.2013.00268

Kuklinsky-Sobral, J., Araújo, W. L., Mendes, R., Pizzirani-Kleiner, A., and Azevedo, J. (2005). Isolation and characterization of endophytic bacteria from soybean (Glycine max) grown in soil treated with glyphosate herbicide. Plant Soil 273, 91-99. doi: 10.1007/s11104-004-6894-1

Martin-Amat, G., McMartin, K. E., Hayreh, S. S., Hayreh, M. S., and Tephly, T. R. (1978). Methanol poisoning: ocular toxicity produced by formate. Toxicol. Appl. Pharmacol. 45, 201-208. doi: 10.1016/0041-008X(78)90040-6

Meyer, F., Paarmann, D., D’Souza, M., Olson, R., Glass, E. M., Kubal, M., et al. (2008). The metagenomics RAST server - a public resource for the automatic phylogenetic and functional analysis of metagenomes. BMC Bioinformatics 9:386. doi: 10.1186/1471-2105-9-386 
Moorthie, S., Mattocks, C. J., and Wright, C. F. (2011). Review of massively parallel DNA sequencing technologies. Hugo J. 5, 1-12. doi: 10.1007/s11568-0119156-3

Muyzer, G., de Waal, E. C., and Uitterlinden, A. G. (1993). Profiling of complex microbial populations by denaturing gradient gel electrophoresis analysis of polymerase chain reaction-amplified genes coding for $16 \mathrm{~S}$ rRNA. Appl. Environ. Microbiol. 59, 695-700.

Noll, M., Matthies, D., Frenzel, P., Derakshani, M., and Liesack, W. (2005). Succession of bacterial community structure and diversity in a paddy soil oxygen gradient. Environ. Microbiol. 7, 382-395. doi: 10.1111/j.14622920.2005.00700.x

O'Connell, J. L., and Nyman, J. A. (2011). Effects of marsh pond terracing on coastal wintering waterbirds before and after Hurricane Rita. Environ. Manage. 48, 975-984. doi: 10.1007/s00267-011-9741-1

Peñuelas, J., Sardans, J., Estiarte, M., Ogaya, R., Carnicer, J., Coll, M., et al. (2013). Evidence of current impact of climate change on life: a walk from genes to the biosphere. Glob. Chang. Biol. 19, 2303-2338. doi: 10.1111/gcb.12143

Phillips, O. L., Aragão, L. E., Lewis, S. L., Fisher, J. B., Lloyd, J., López-González, G., et al. (2009). Drought sensitivity of the Amazon rainforest. Science 323, 1344-1347. doi: 10.1126/science.1164033

R Development Core Team. (2008). R: A Language and Environment for Statistical Computing. R Foundation for Statistical Computing. http://www.R-project.org

Rota, C. T., Millspaugh, J. J., Rumble, M. A., Lehman, C. P., and Kesler, D. C. (2014). The role of wildfire, prescribed fire, and mountain pine beetle infestations on the population dynamics of black-backed woodpeckers in the black hills, South dakota. PLoS ONE 9:e94700. doi: 10.1371/journal.pone.0094700

Schloss, P. D., Westcott, S. L., Ryabin, T., Hall, J. R., Hartmann, M., Hollister, E. B., et al. (2009). Introducing mothur: open-source, platform-independent, community-supported software for describing and comparing microbial communities. Appl. Environ. Microbiol. 75, 7537-7541. doi: 10.1128/AEM. 01541-09

Singh, B. K. (2009). Organophosphorus-degrading bacteria: ecology and industrial applications. Nat. Rev. Microbiol. 7, 156-164. doi: 10.1038/nrmicro2050

Singh, B. K., and Walker, A. (2006). Microbial degradation of organophosphorus compounds. FEMS Microbiol. Rev. 30, 428-471. doi: 10.1111/j.15746976.2006.00018.x

Spillner, C. J., DeBaun, J. R., and Menn, J. J. (1979). Degradation of fenitrothion in forest soil and effects on forest soil microbes. J. Agric. Food Chem. 27, 1054-1060. doi: 10.1021/jf60225a009

Suárez-Moreno, Z. R., Caballero-Mellado, J., Coutinho, B. G., Mendonça-Previato, L., and James, E. K. (2012). Common features of environmental and potentially beneficial plant-associated Burkholderia. Microb. Ecol. 63, 249-266. doi: 10.1007/s00248-011-9929-1
Tago, K., Sekiya, E., Kiho, A., Katsuyama, C., Hoshito, Y., Yamada, N., et al. (2006). Diversity of fenitrothion-degrading bacteria in soils from distant geographical areas. Microbes Environ. 21, 58-64. doi: 10.1264/jsme2.21.58

Tamura, K., Dudley, J., Nei, M., and Kumar, S. (2007). MEGA4: molecular Evolutionary Genetics Analysis (MEGA) software version 4.0. Mol. Biol. Evol. 24, 1596-1599. doi: 10.1093/molbev/msm092

Tehara, S. K., and Keasling, J. D. (2003). Gene cloning, purification, and characterization of a phosphodiesterase from Delftia acidovorans. Appl. Environ. Microbiol. 9, 504-508. doi: 10.1128/AEM.69.1.504-508.2003

Wang, Q., Garrity, G. M., Tiedje, J. M., and Cole, J. R. (2007). Naïve bayesian classifier for rapid assignment of rRNA Sequences into the new bacterial taxonomy. Appl. Environ. Microbiol. 73, 5261-5267. doi: 10.1128/AEM.00062-07

Whalon, M. E., Monte-Sanchez, D., and Hollingworth, R. M. (2008). Global Pesticide Resistance in Arthropods. London: CAB International. doi: $10.1079 / 9781845933531.0000$

Wilson, M. C., and Piel, J. (2013). Metagenomic approaches for exploiting uncultivated bacteria as a resource for novel biosynthetic enzymology. Chem. Biol. 20, 636-647. doi: 10.1016/j.chembiol.2013.04.011

Zhang, R., Cui, Z., Jiang, J., He, J., Gu, X., and Li, S. (2005). Diversity of organophosphorus pesticide-degrading bacteria in a polluted soil and conservation of their organophosphorus hydrolase genes. Can. J. Microbiol. 51, 337-343. doi: 10.1139/w05-010

Zhang, Z., Hong, Q., Xu, J., Zhang, X., and Li, S. (2006). Isolation of fenitrothion-degrading strain Burkholderia sp. FDS-1 and cloning of mpd gene. Biodegradation 17, 275-283. doi: 10.1007/s10532-005-7130-2

Conflict of Interest Statement: The authors declare that the research was conducted in the absence of any commercial or financial relationships that could be construed as a potential conflict of interest.

Received: 08 May 2014; accepted: 12 August 2014; published online: 29 August 2014. Citation: Itoh H, Navarro R, Takeshita K, Tago K, Hayatsu M, Hori T and Kikuchi $Y$ (2014) Bacterial population succession and adaptation affected by insecticide application and soil spraying history. Front. Microbiol. 5:457. doi: 10.3389/fmicb. 2014.00457

This article was submitted to Systems Microbiology, a section of the journal Frontiers in Microbiology.

Copyright (c) 2014 Itoh, Navarro, Takeshita, Tago, Hayatsu, Hori and Kikuchi. This is an open-access article distributed under the terms of the Creative Commons Attribution License (CC BY). The use, distribution or reproduction in other forums is permitted, provided the original author(s) or licensor are credited and that the original publication in this journal is cited, in accordance with accepted academic practice. No use, distribution or reproduction is permitted which does not comply with these terms. 